\title{
DUALITY PROBLEM FOR THE CLASS OF LIMITED COMPLETELY CONTINUOUS OPERATORS
}

\author{
J. H’Michane, A. El Kaddouri, K. Bouras And M. Moussa
}

Abstract. We establish necessary and sufficient conditions under which the class $L_{c c}(E, F)$ of limited completely continuous operators between two Banach lattices verifies the direct and reciprocal duality property.

Mathematics subject classification (2010): 46B42, 47B60, 47B65.

Keywords and phrases: Limited operator, limited sets, Dunford-Pettis ${ }^{\star}$ property, Order continuous norm.

\section{REFERENCES}

[1] C. D. Aliprantis and O. Burkinshaw, Positive operators, Reprint of the 1985 original. Springer, Dordrecht, 2006.

[2] B. Aqzzouz And J. Hmichane, Some results on order weakly compact operators, Mathematica Bohemica, Vol. 134 (2009), No. 4, 359-367.

[3] B. Aqzzouz, A. Elbour And J. Hmichane, The duality problem for the class of b-weakly compact operators, Positivity 13 (2009), 4, 683-692.

[4] J. Bourgain AND J. Diestel., Limited operators and strict cosingularity, Math. Nachr. 119 (1984), $55-58$.

[5] P. G. DodDs, o-weakly compact mappings of Riesz spaces, Trans. Amer. Math. Soc. 214 (1975), 389-402.

[6] P. G. Dodds, AND D. H. Fremlin, Compact operators on Banach lattices, Israel J. Math. 34 (1979), 287-320.

[7] L. Drewnows Ki, On Banach spaces with the Gelfand-Phillips property, Math. Z. 193 (1986), 405411.

[8] P. Meyer-Nieberg, Banach lattices, Universitext, Springer-Verlag, Berlin, 1991.

[9] M. Salimi And S. M. Moshtaghioun, The Gelfand-Phillips property in closed subspaces of some operator spaces, Banach Journal of Mathematical Analysis, vol. 5, no. 2, pp. 84-92, 2011.

[10] W. WNuK, Banach Lattices with Order Continuous Norms, Polish Scientific Publishers, Warsaw, 1999. 